\title{
New insight into increased angiotensin II type 1 receptor expression in $\mathrm{Snx} 1^{-1-}$ mice
}

\author{
Shin-ichiro Miura ${ }^{1,2}$
}

Received: 3 April 2021 / Revised: 7 April 2021 / Accepted: 8 April 2021 / Published online: 20 May 2021

(c) The Japanese Society of Hypertension 2021

The renin-angiotensin system (RAS) consists of angiotensinogen, renin, angiotensin-converting enzyme, angiotensin II (Ang II) and the Ang II type $1\left(\mathrm{AT}_{1}\right)$ and type 2 $\left(\mathrm{AT}_{2}\right)$ receptors [1]. RAS activities regulate blood pressure (BP), blood volume, cell proliferation and differentiation, metastasis, and tissue remodeling. Several new findings focused on topics including Ang 1-7, $\mathrm{AT}_{2} / \mathrm{Mas}$, and $\mathrm{AT}_{4}$ insulin-regulated membrane aminopeptidase, several Ang II-generating enzymes, and $\mathrm{AT}_{1} / \mathrm{AT}_{2}$ heterodimerization have been reported over the past few decades.

The sorting nexin 1 (SNX) family is composed of a diverse group of cytoplasmic and membrane-associated proteins that are involved in various aspects of receptor endocytosis and trafficking through endosomes [2-4]. Endocytosis and trafficking are also important functions of $\mathrm{G}$ protein-coupling receptors (GPCRs), including the $\mathrm{AT}_{1}$ and $\mathrm{AT}_{2}$ receptors. For example, while SNX1 binds two dopamine receptors $\left(\mathrm{D}_{1}\right.$ and $D_{5}$ receptors), which are GPCRs, it binds only the $D_{5}$ receptor strongly $[5,6]$. Recently, $\mathrm{Snx}^{-1-}$ mice were shown to have high $\mathrm{BP}$ associated with increased renal expression of the $\mathrm{AT}_{1}$ receptor, nicotinamide adenine dinucleotide phosphate oxidase subunits, $\mathrm{D}_{5}$ receptor, and sodium chloride cotransporter [7]. Acute renal-restricted depletion of SNX1 resulted in a blunted natriuretic response and high BP in mice due to impaired $\mathrm{D}_{5}$ receptor activity. In addition, several SNX1 SNPs were shown to be associated with an antihypertensive response to hydrochlorothiazide monotherapy among hypertensive African Americans in the Pharmacogenomic Evaluation of Antihypertensive Responses study. More recently, providing greater mechanistic precision, in this issue of

Shin-ichiro Miura

miuras@cis.fukuoka-u.ac.jp

1 Department of Cardiology, Fukuoka University School of Medicine, Fukuoka, Japan

2 Department of Internal Medicine, Fukuoka University Nishijin Hospital, Fukuoka, Japan
Hypertension Research, Liu et al. successfully report that Ang II-induced contraction of mesenteric arteries was much greater in $\mathrm{Snx}^{-/-}$mice than in WT mice, whereas there was no obvious difference in phenylephrine-induced contraction between the mice [8]. Interestingly, $\mathrm{AT}_{1}$ receptor protein levels in the aorta were significantly elevated in the $\mathrm{Snx}^{-/-}$ mice. In addition, the authors found that $\mathrm{AT}_{1}$ receptor protein levels, but not $\mathrm{AT}_{1}$ receptor mRNA levels, were elevated after SNX1 knockdown, probably independent of the $\mathrm{D}_{5}$ receptor, which indicated that SNX1 may be involved in the process of $\mathrm{AT}_{1}$ receptor protein degradation. This may represent a novel mechanism for the regulation of BP.

Proteasomes and lysosomes are the two most important proteolytic machines in cells [9]. In this study, proteasomal inhibition, rather than lysosomal inhibition, increased AT1R expression in embryonic thoracic aortic smooth muscle cells [8]. Systemic administration of proteasome inhibitors suppressed pressure-overload cardiac hypertrophy and benefitted long-term cardiac remodeling in animal models [10]. On the other hand, a proteasome inhibitor promoted maladaptive remodeling in surviving mice with transverse aortic constriction and activated the calcineurin-nuclear factor of activated $T$ cells pathway in cardiomyocytes in vitro and in vivo [11]. Thus, the cause of this conflict in the data is unclear at this time. Notably, there has been a wealth of discussion on the effects of proteasome inhibition on vascular function and remodeling, which reduce high BP [12]. Proteasomal functional insufficiency is a major pathogenic factor in the cardiovascular system. Finally, this study provides useful information due to the finding that SNX1mediated $\mathrm{AT}_{1}$ receptor degradation occurs mainly through the proteasomal pathway [8].

The Fig. 1 shows possible mechanisms for the interaction between the $\mathrm{AT}_{1}$ receptor and SNX1. Functional SNX1 initiates Ang II-mediated $\mathrm{AT}_{1}$ receptor activation at the plasma membrane, which results in dissociation of the $\mathrm{G}$ protein from the receptor and activates signal transduction (high blood pressure signaling), subsequently inducing receptor internalization and trafficking (Fig. 1A). Thus, 
A. Functional SNX1

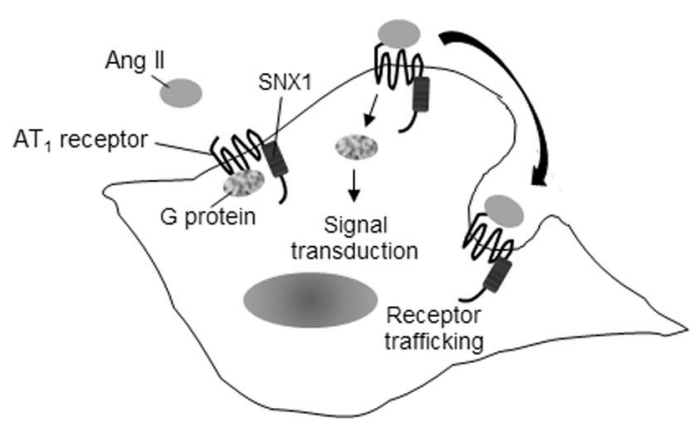

B. Dysfunctional SNX1

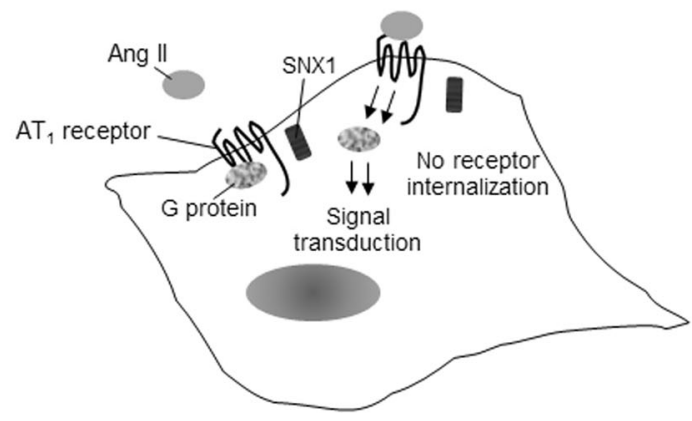

Fig. 1 Possible mechanisms for the interaction between the $\mathrm{AT}_{1}$ receptor and functional (A) or dysfunctional (B) SNX1

functional SNX1 optimally regulates $\mathrm{AT}_{1}$ receptor degradation. On the other hand, dysfunctional SNX1 results in failed agonist-activated receptor internalization and the continued presence of indices of high BP signaling and does not regulate $\mathrm{AT}_{1}$ receptor degradation or increase receptor expression Fig. 1B.

In conclusion, this new model of the development of hypertension implies that the trafficking protein SNX1 may be a crucial target of hypertension and antihypertensive therapy.

\section{Compliance with ethical standards}

Conflict of interest The author declares no competing.

Publisher's note Springer Nature remains neutral with regard to jurisdictional claims in published maps and institutional affiliations.

\section{References}

1. Ziaja M, Urbanek KA, Kowalska K, Piastowska-Ciesielska AW. Angiotensin II and angiotensin receptors 1 and 2-multifunctional system in cells biology, what do we know? Cells. 2021;10:381.

2. Yang J, Villar VAM, Rozyyev S, Jose PA, Zeng C. The emerging role of sorting nexins in cardiovascular diseases. Clin Sci. 2019;133:723-37.

3. Bonifacino JS, Hurley JH. Retromer. Curr Opin Cell Biol. 2008;20:427-36.
4. Brandizzi F, Wasteneys GO. Cytoskeleton-dependent endomembrane organization in plant cells: an emerging role for microtubules. Plant J. 2013;75:339-49.

5. Villar VA, Jones JE, Armando I, Asico LD, Escano CS Jr, Lee H, et al. Sorting nexin 1 loss results in D5 dopamine receptor dysfunction in human renal proximal tubule cells and hypertension in mice. J Biol Chem. 2013;288:152-63.

6. Heydorn A, Sondergaard BP, Hadrup N, Holst B, Haft CR, Schwartz TW. Distinct in vitro interaction pattern of dopamine receptor subtypes with adaptor proteins involved in postendocytotic receptor targeting. FEBS Lett. 2004;556:276-80.

7. Yang J, Asico LD, Beitelshees AL, Feranil JB, Wang X, Jones JE, et al. Sorting nexin 1 loss results in increased oxidative stress and hypertension. FASEB J. 2020;34:7941-57.

8. Liu C, Li X, Fu J, Chen K, Liao Q, Wang J, et al. Increased $\mathrm{AT}_{1}$ receptor expression mediates vasoconstriction leading to hypertension in Snx1 ${ }^{-1-}$ mice. Hypertens Res. 2021. https://doi.org/10. 1038/s41440-021-00661-x.

9. Wang X, Robbins J. Proteasomal and lysosomal protein degradation and heart disease. J Mol Cell Cardiol. 2014;71: $16-24$.

10. Depre C, Wang Q, Yan L, Hedhli N, Peter P, Chen L, et al. Activation of the cardiac proteasome during pressure overload promotes ventricular hypertrophy. Circulation. 2006;114: 1821-8.

11. Tang M, Li J, Huang W, Su H, Liang Q, Tian Z, et al. Proteasome functional insufficiency activates the calcineurin-NFAT pathway in cardiomyocytes and promotes maladaptive remodelling of stressed mouse hearts. Cardiovasc Res. 2010;88:424-33.

12. Li S, Wang X, Li Y, Kost CK Jr, Martin DS. Bortezomib, a proteasome inhibitor, attenuates angiotensin II-induced hypertension and aortic remodeling in rats. PLoS ONE. 2013;8:e78564. 